\title{
Effect of pH on Crystal Size and Photoluminescence Property of ZnO Nanoparticles Prepared by Chemical Precipitation Method
}

\author{
M. Jay Chithra $\cdot$ M. Sathya $\cdot$ K. Pushpanathan
}

Received: 30 April 2014/Revised: 18 August 2014/Published online: 23 January 2015

(c) The Chinese Society for Metals and Springer-Verlag Berlin Heidelberg 2015

\begin{abstract}
The effects of $\mathrm{pH}$ value on crystal size and optical property of zinc oxide nanoparticles prepared by chemical precipitation method were investigated. Prepared samples have been characterized by means of X-ray diffraction, scanning electron microscopy, ultraviolet-visible spectrometer and photoluminescence spectrometer. From X-ray diffraction profile, it is found that the particle size of sample increases from 13.8 to $33 \mathrm{~nm}$ when the $\mathrm{pH}$ value of the solution was increased from 6 to 13. Microstructural study also shows that the particle size increases with $\mathrm{pH}$ value. Hexagonal shape of the zinc oxide nanoparticle has been confirmed by the scanning electron microscopy image. The recorded ultraviolet-visible spectrum shows excitonic absorption peaks around $381 \mathrm{~nm}$. The energy gap of the prepared samples has been determined from the ultraviolet-visible absorption spectrum, effective mass model equation and Tauc's relation. It was found that the energy gap of the prepared samples decreases with increase in $\mathrm{pH}$ value. The recorded blue shift confirmed the quantum confinement effect in the prepared zinc oxide samples. Photoluminescence spectrum infers that the increase in $\mathrm{pH}$ value shifts the ultraviolet-visible emission but not the violet and green emissions.
\end{abstract}

KEY WORDS: Zinc oxide nanoparticles; pH value; Crystal structure; Microstructure; Energy gap; Photoluminescence

\section{Introduction}

Zinc oxide $(\mathrm{ZnO})$ is one of the promising non-toxic and IIVI group semiconductor materials [1,2]. In recent years, many researchers are working on solution-grown $\mathrm{ZnO}$ nanomaterials due to its extraordinary electrical and optical characteristics, required for nanoscaled electronic and optoelectronic devices [3-6]. In comparison with other wide band gap semiconductors, $\mathrm{ZnO}$ possesses a band gap of $3.37 \mathrm{eV}$ with large exciton binding energy of $60 \mathrm{meV}$ which ensures an efficient ultraviolet (UV) and blue emission at

Available online at http://link.springer.com/journal/40195

M. Jay Chithra $\cdot$ M. Sathya $\cdot$ K. Pushpanathan $(\bowtie)$

PG \& Research Department of Physics, Government Arts

College, Karur 639 005, Tamilnadu, India

e-mail: kpngackr@yahoo.co.in room temperature $[4,5]$. It is reported that $\mathrm{ZnO}$ possesses higher quantum efficiency, good stability against photocorrosion and photochemical properties, and ability to grow high-quality single crystal with cost effectiveness. Also, it is an inexpensive luminescent and bio-friendly oxide semiconductor material. As a result of the properties affirmed above, $\mathrm{ZnO}$ is expected to have an extensive applications in UV laser [7], biosensors [8], bio-imaging [9], drug delivery [10], piezoelectric transducers [11], dye-sensitized solar cells [12], high sensitivity chemical gas sensor [13], volatile organic compound sensor [14], DNA sequence sensor [15], short wavelength (green, blue, UV) optoelectronic devices [16], light-emitting diodes [17] and field-effect transistors [18]. Recent development in nanotechnology uses the $\mathrm{ZnO}$ nanostructure as cantilever in scanning electron microscope (SEM) with a size that is 500 times smaller than the conventional cantilever, which offers improved sensitivity and mechanical flexibility [19]. 
In the area of bioengineering, $\mathrm{ZnO}$ has been investigated for the growth control of Saccharomyces cerevisiae bacteria [20, 21] and microalgae [22]. As it is biocompatible and biodegradable, $\mathrm{ZnO}$ wires are used in biosensors and biological systems [23]. With the alertness of the anticancer effect of photo-excited $\mathrm{ZnO}$, guided delivery of $\mathrm{ZnO}$-based drugs has become a topic of interest [24]. It is envisaged that magnetic $\mathrm{ZnO}$ composites in the form of capsules or nanosubmarines can be magnetically guided to a desired location of a human body. As a result, there would be significant enhancement of $\mathrm{ZnO}$ efficiency and large reduction in dosage and cost. Because of these interesting features, many research groups have chosen this material.

A wide range of physical and chemical methods have been adopted by different research groups for the synthesis of $\mathrm{ZnO}$ nanoparticles such as chemical precipitation, solgel synthesis, hydrothermal reaction and electrochemical routes. Extensive literature assessment infers that chemical precipitation method is the foremost method for the synthesis of $\mathrm{ZnO}$ nanoparticles. As chemical precipitation is a low-temperature process, and its easy procedure to control the particle size and its low cost, this method finds suitable application in microelectronics and plastic electronics also. It is reported that [25] precipitation method yields the smallest nanoparticle with best optical and photocatalytic activity, compared with other methods mentioned above. Due to these reasons, precipitation method has been adopted for the present work.

Apart from synthesis procedure, some other parameters like reaction temperature, $\mathrm{pH}$ value of the solution, aging time, concentration of the precursors, amount of modifier, type of modifier and the solvent used also play a key role in nucleation and growth of $\mathrm{ZnO}$ nanoparticles. A number of investigations have been focused on the synthesis and characterization of $\mathrm{ZnO}$ nanoparticles, but only a very few articles deal with the effect of $\mathrm{pH}$ value on crystal size and energy gap of $\mathrm{ZnO}$ nanoparticles prepared by chemical precipitation method. For example, Li et al. [26] investigated the effects of temperature, $\mathrm{pH}$ value and precursors on the particle size. They found that $\mathrm{pH}$ of the solution has a certain effect on scheming the particle size. In similar study, Zhang et al. [27] reported that $\mathrm{pH}$ value is the main factor that influences the morphology of the nanoparticles. Since, $\mathrm{pH}$ value affects the formation of nuclei and growth environment of $\mathrm{ZnO}$. Lu and Yeh [28] observed the remarkable variation in the morphology of $\mathrm{ZnO}$ powder from an ellipsoidal shape to a rod-like shape, as the $\mathrm{pH}$ value of the solution increased from 9 to 12 in a hydrothermal reaction. They considered that the nucleation profoundly depends on the $\mathrm{pH}$ of the starting solutions. In similar fashion, Rani et al. [29] found to increase in crystalline size $(14 \mathrm{~nm})$ with $\mathrm{pH}$ value from 6 to 9 , thereafter the crystalline size decreases to around $12 \mathrm{~nm}$ when the $\mathrm{pH}$ value of the solution was further increased to 11. Conversely, Alias et al. [30] investigated the effect of $\mathrm{pH}$ value on the structural and optical properties of $\mathrm{ZnO}$ nanopowders synthesized by sol-gel centrifugation method without capping agent. Based on their result, they concluded that the particle size decreases with increase in $\mathrm{pH}$ value. It is clear from these earlier reports that a few authors claimed that the particle size of $\mathrm{ZnO}$ nanoparticles increases with $\mathrm{pH}$ value and few authors found that it decreases with $\mathrm{pH}$ value.

In this context, an attempt has been made to investigate the effect of $\mathrm{pH}$ on crystalline size, microstructure and bandgap of $\mathrm{ZnO}$ nanoparticles synthesized via precipitation method. For this, pH value of solution has been adjusted in a wide range from 6 to 13. Our result favors for the increase in particle size with $\mathrm{pH}$ value. The crystallite size and microstructure of the synthesized nanopowders found to depend strongly on the $\mathrm{pH}$ value of solution. The novelty of the present work is that the chemical precipitation method is a suitable method for producing the $\mathrm{ZnO}$ nanoparticles of size around $14 \mathrm{~nm}$. Our investigation carries further information that the preparation approach discussed here is suitable for the construction of violet emission optoelectronic and nano-photonic devices.

\section{Materials and Methods}

\subsection{Synthesis of $\mathrm{ZnO}$ Nanopowder}

ZnO Nanoparticles were successfully synthesized by an extremely simple precipitation method using analytical grade zinc acetate di-hydrate $\left[\mathrm{Zn}\left(\mathrm{CH}_{3} \mathrm{COOH}\right)_{2} \cdot 2 \mathrm{H}_{2} \mathrm{O}\right.$ $99.5 \%$, Merck] and sodium hydroxide ( $\mathrm{NaOH}$, Merck). These chemicals were used without further purification. Four samples were synthesized for the present study by varying the $\mathrm{pH}$ value of the solution. A transparent $0.2 \mathrm{~mol} / \mathrm{L}$ zinc acetate di-hydrate $\left[\mathrm{Zn}\left(\mathrm{CH}_{3} \mathrm{COOH}\right)_{2} \cdot 2 \mathrm{H}_{2} \mathrm{O}\right]$ solution was prepared in ethanol $(99.7 \%$ purity) under vigorous stirring at room temperature $\left(30{ }^{\circ} \mathrm{C}\right)$ and the same solution was used for all the four samples. For the synthesis of $\mathrm{ZnO}$ sample at $\mathrm{pH}$ value of $6,150 \mathrm{~mL}$ of $0.2 \mathrm{~mol} / \mathrm{L}$ zinc acetate di-hydrate solution was taken in a beaker. With this solution, certain amount of sodium hydroxide $(\mathrm{NaOH})$ pellets was directly dropped into the solution till the $\mathrm{pH}$ value of the solution reaches 6. Elico LI 120 digital $\mathrm{pH}$ meter was used to measure the $\mathrm{pH}$ value of the solution. The milky white solution obtained so was stirred with magnetic stirrer for $7 \mathrm{~h}$. Following this, $2 \mathrm{~mL}$ of polyethylene glycol (PEG MW: 400), capping agent, was added to the mixture of zinc acetate and sodium hydroxide solution, and the same was kept in an airtight container for a day towards the slow crystallization. Consequently, $\mathrm{ZnO}$ precipitation settled down at the bottom of the beaker. Then, the sodium acetate $\left[\mathrm{Na}\left(\mathrm{CH}_{3} \mathrm{COO}\right)\right]$ transparent solution 
was removed, and the particles were washed with ethanol several times. The particles thus obtained was filtered and dried at $80{ }^{\circ} \mathrm{C}$ for $10 \mathrm{~h}$ in a hot air oven to remove the remaining water content from the sample. Since the ethanol has longer chain length and it fastens the nucleation and growth of nanoparticles, the ethanol has been chosen as solvent. This is the reason for synthesizing samples with ethanol. Similar procedure was followed for the synthesis of samples at $\mathrm{pH}$ values of 8,12 and 13 . The overall reaction involved in the synthesis process can be written as

$$
\begin{aligned}
& \mathrm{Zn}\left(\mathrm{CH}_{3} \mathrm{COO}\right)_{2} \cdot 2 \mathrm{H}_{2} \mathrm{O}+2 \mathrm{NaOH} \\
& \rightarrow \mathrm{Zn}(\mathrm{OH})_{2}+2 \mathrm{Na}\left(\mathrm{CH}_{3} \mathrm{COO}\right)+2 \mathrm{H}_{2} \mathrm{O} \\
& \mathrm{Zn}(\mathrm{OH})_{2}+2 \mathrm{H}_{2} \mathrm{O} \rightarrow \mathrm{Zn}^{2+}+2 \mathrm{OH}^{-}+2 \mathrm{H}_{2} \mathrm{O} \\
& \rightarrow \mathrm{Zn}(\mathrm{OH})_{4}^{2-}+2 \mathrm{H}^{+} \\
& \mathrm{Zn}(\mathrm{OH})_{4}^{2-} \rightarrow \mathrm{ZnO}+\mathrm{H}_{2} \mathrm{O}+2 \mathrm{OH}^{-} .
\end{aligned}
$$

\subsection{Characterization of $\mathrm{ZnO}$ Powder}

Crystalline nature of the samples was acknowledged using Philips Analytical X-ray diffractometer (Model No. PW1830) equipped with Ni-filtered $\mathrm{Cu} K_{\alpha}$ radiation $(\lambda=0.154187 \mathrm{~nm})$ for $2 \theta=30^{\circ}-80^{\circ}$, with scanning rate of $5 \% \mathrm{~min}$ operated at $40 \mathrm{kV} / 30 \mathrm{~mA}$. Topographical and elemental information of the samples were examined by using a scanning electron microscope (SEM-U9320A 8500: Agilent Technologies, Inc. USA) operated at $20 \mathrm{kV} / 20 \mathrm{~mA}$. For SEM observation, powder was uniformly sprayed on a carbon tape pasted on the specimen holder. In order to avoid charging while observation, the powder was coated with a thin layer of osmium tetroxide $(\sim 10 \mathrm{~nm})$. JEM-1010 transmission electron microscope (TEM) was used to study the sample morphology and size. Synthesized nanopowders were dispersed in double distilled water, and then, the absorption and transmittance properties were studied by using Lambda 35 (PERKINELMER: USA) Ultraviolet-visible (UV-Vis) spectrophotometer. The functional group of the synthesized $\mathrm{ZnO}$ nanoparticles was characterized by the Fourier transform infrared (FTIR) spectroscopy in the range of $4,000-400 \mathrm{~cm}^{-1}$. The photoluminescence (PL) measurements were carried out at room temperature by means of PL spectrometer (Kimon, SPEC-14031K, Japan) with a He-Cd laser line of $325 \mathrm{~nm}$ as the excitation source.

\section{Results and Discussion}

\subsection{X-ray Diffraction Analysis and Energy Gap Calculation}

The result of room temperature X-ray diffraction pattern (XRD) of the prepared samples is shown in Fig. 1. The

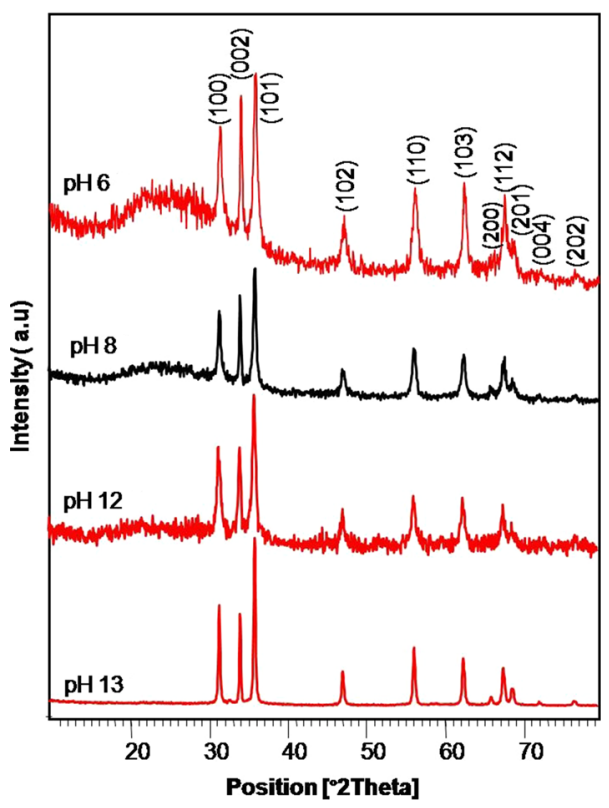

Fig. $1 \mathrm{XRD}$ spectra of $\mathrm{ZnO}$ nanoparticles synthesized via precipitation method at different $\mathrm{pH}$ values

sharp and most intense peaks observed here indicate that the synthesized $\mathrm{ZnO}$ nanoparticles are of high crystalline nature with single phase. The strong diffraction peaks appear at $31.8^{\circ}, 33.4^{\circ}, 36.2^{\circ}, 47.5^{\circ}, 56.5^{\circ}, 62.8^{\circ}, 66.3^{\circ}, 67.9^{\circ}, 69^{\circ}$, $72.6^{\circ}$ and $76.9^{\circ}$ corresponding to (100), (002),(101), (102), (110), (103), (200), (112), (201), (004) and (202) planes matches well with those of the wurtzite structure of $\mathrm{ZnO}$ crystal. It should be noted that except the diffraction peaks of $\mathrm{ZnO}$, no other peaks of impurity (or) unreacted phase could be observed. The average crystallite size, $D$, has been obtained from the highest diffraction peak along the $<101>$ plane using the Debye-Scherrer formula [31] as follows:

$D=\frac{0.9 \lambda}{\beta \cos \theta}$,

where $\lambda$ is the wavelength of the employed $\mathrm{Cu} K_{\alpha}$ radiation $(0.154 \mathrm{~nm}), \beta$ is the full width at half-maximum (FWHM) of the peaks, and $\theta$ is the Bragg angle obtained from $2 \theta$ value corresponding to maximum intensity peak in XRD pattern. The average crystallite size calculated across 13.8, 18.0, 24.7 and $33 \mathrm{~nm}$ for the samples obtained at $\mathrm{pH}$ values of $6,8,12$ and 13 , respectively. Calculation depicts that the average crystallite size increases with increase in $\mathrm{pH}$ value of the solution just like the case of increase in diameter of the $\mathrm{ZnO}$ nanorods grown in similar method [4]. Also, it clearly shows that an increase in $\mathrm{pH}$ value helps in nucleation and growth of nanoparticles. As a matter of fact that the acid can restrain the hydrolysis and alkali can accelerate the hydrolysis in a chemical reaction. The low $\mathrm{pH}$ value of 6 corresponds to acidic nature of the solution and it could restrain the particle growth. When the $\mathrm{pH}$ 
value is greater than 7 , totally alkali environment supports in hydrolysis and this enhances particle growth, thereby increasing the particle size. Similar increase in particle size with $\mathrm{pH}$ value has also been reported [32,33]. Based on the recorded XRD pattern, synthesized $\mathrm{ZnO}$ nanopowders are indexed as wurtzite hexagonal closely packed structure (space group: p63 mc) and its lattice constants $a$ and $c$ were determined from the following equation using the interplanar distance $d$ and $(h k l)$ values of the XRD profile.

$\frac{1}{d^{2}}=\frac{4}{3}\left\{\frac{h^{2}+h k+l^{2}}{a^{2}}\right\}+\frac{l^{2}}{c^{2}}$.

The calculated lattice parameters, shown in Table 1, are very close to those available in standard JCPDS data No. $36-1451 \quad(a=0.3251 \mathrm{~nm}$ and $c=0.5212 \mathrm{~nm})$. It is interesting to note that the intensity of the (100) and (101) peaks found to increase with $\mathrm{pH}$ value. In all the samples, intensity of (101) peak is maximum. However, the intensity of (002) peak of $\mathrm{pH}$ value of 6 is higher than that of $\mathrm{pH}$ value of 13 ; i.e., intensity of the (002) peak decreases with the increase in $\mathrm{pH}$ value of the solution. This infers that increase in $\mathrm{pH}$ value limits the accumulation of atoms in (002) plane.

In general, energy gap of nanoparticles are inversely proportional to its radius. Therefore, the energy gap of the $\mathrm{ZnO}$ nanoparticles have been evaluated from the effective mass model expression [34], as given below

$$
\begin{aligned}
E_{\mathrm{g}}^{\text {nano }}= & E_{\mathrm{g}}^{\text {bulk }}+\frac{h^{2}}{8 e r^{2}}\left[\frac{1}{m_{\mathrm{e}}^{*}}+\frac{1}{m_{\mathrm{h}}^{*}}\right]-\frac{1.8 e^{2}}{4 \pi r \varepsilon \varepsilon_{0}} \\
& -\frac{0.124 e^{3}}{\hbar^{3}\left(4 \pi \varepsilon \varepsilon_{0}\right)^{2}}\left[\frac{1}{m_{\mathrm{e}}^{*}}+\frac{1}{m_{\mathrm{h}}^{*}}\right]^{-1},
\end{aligned}
$$

where, the first term, $E_{\mathrm{g}}^{\text {bulk }}$ corresponds the energy gap of bulk $\mathrm{ZnO}(3.37 \mathrm{eV})$, second term corresponds the quantum confinement effect and the third term is related to coulomb interaction. Here, $r$ is the radius of the crystal calculated from the XRD analysis, $m_{\mathrm{e}}^{*}$ is the effective mass of the electron $\left(0.24 m_{\mathrm{o}}\right), m_{\mathrm{h}}^{*}$ is the effective mass of hole $(0.59$ $\left.m_{\mathrm{o}}\right), m_{\mathrm{o}}$ is the rest mass of the electron $\left(9.110 \times 10^{-31} \mathrm{~kg}\right)$, $\varepsilon$ is the relative permittivity (8.66), $\varepsilon_{0}$ is the permittivity of free space $\left(8.854 \times 10^{-12} \mathrm{~F} / \mathrm{m}\right), h$ is Planck's constant $\left(6.626 \times 10^{-34} \mathrm{Js}\right)$, and $e$ is the charge of the electron $\left(1.602 \times 10^{-19} \mathrm{C}\right)$. By substituting these values, the above Eq. (3) can be simplified as

$E_{\mathrm{g}}^{\mathrm{nano}}=E_{\mathrm{g}}^{\mathrm{bulk}}+\frac{1.6}{r^{2}}$.

The energy gap calculated to be $3.42,3.40,3.39$ and $3.38 \mathrm{eV}$ for the samples prepared at $\mathrm{pH}$ values of $6,8,12$ and 13 , respectively. As the sample prepared at $\mathrm{pH}$ value of 6 has smaller particles, its energy gap is greater than that of the sample prepared at $\mathrm{pH}$ value of 13 . It proves that energy gap of the nanoparticle is inversely proportional to its radius. Therefore, from the XRD analysis, it is confirmed that chemical precipitation method is a suitable method for the synthesis of $\mathrm{ZnO}$ nanoparticles, and it provides a generic approach for producing the highquality $\mathrm{ZnO}$ nanoparticles.

\subsection{Dislocation Density and Micro-Strain Calculation}

The dislocation density, $S$, is a measure of amount of defects and vacancies in the crystal which can be determined from the crystallite size $(D)$ using the formula

$S=\frac{1}{D^{2}}$.

It can be seen from Table 1 that $S$ increases from $5.3 \times 10^{15}$ to $9.2 \times 10^{15}$ with increasing $\mathrm{pH}$ value. It indicates that the lattice imperfection increases with particle size. Similarly, micro-strain $(\varepsilon)$ has also been calculated using the formula

$\varepsilon=\frac{\beta \cos \theta}{4}$.

From Table 1, it can be found that the micro-strain of the sample increases with $\mathrm{pH}$ value from 6 to 8, thereafter it decreases. On the whole, variation in micro-strain may be due to the change in microstructure, size and shape and defects of the particles. The increase in strain at $\mathrm{pH}$ value increases from 6 to 8 may be due to the creation of defects in the lattice. But the atoms trapped in the non-equilibrium

\begin{tabular}{|c|c|c|c|c|c|c|c|c|c|c|c|}
\hline $\mathrm{pH}$ value & $2 \theta(101)\left(^{\circ}\right)$ & FWHM $\left(^{\circ}\right)$ & $D(\mathrm{~nm})$ & $d(\mathrm{~nm})$ & $a(\mathrm{~nm})$ & $c(\mathrm{~nm})$ & $V\left(\mathrm{~nm}^{3}\right)$ & $V\left(\mathrm{~nm}^{3}\right)$ & $S$ & $\varepsilon\left(10^{-3}\right)$ & $L(\AA)$ \\
\hline 6 & 36.15 & 0.60 & 13.8 & 0.2821 & 0.3258 & 0.5218 & 1,377 & 0.144 & 5.3 & 1.03 & 1.8935 \\
\hline 8 & 36.17 & 0.46 & 18.0 & 0.2822 & 0.3233 & 0.5260 & 3,055 & 0.142 & 3.1 & 1.49 & 1.8995 \\
\hline 12 & 36.21 & 0.35 & 24.7 & 0.2818 & 0.3259 & 0.5218 & 7,893 & 0.144 & 1.6 & 1.41 & 1.8939 \\
\hline 13 & 36.16 & 0.25 & 33.0 & 0.2823 & 0.3233 & 0.5260 & 18,822 & 0.143 & 9.2 & 0.99 & 1.8935 \\
\hline
\end{tabular}

Table 1 Summary of the characteristics of the $\mathrm{ZnO}$ nanoparticles synthesized at various $\mathrm{pH}$ values

$D$ is average particle size; $d$ is (101) plane space; $V$ is the volume of the particle; $v$ is the volume of the unit cell; $S=\left(1 / D^{2}\right) \times 10^{15}$ is the dislocation density; $\varepsilon$ is micro-strain; and $L$ is bond length 
position could shift toward equilibrium position, and it could release the strain. Hence, the micro-strain decreases as the $\mathrm{pH}$ value increases from 8 to 13 . Furthermore, the observed decrease in FWHM may be due to the particle size or microstrain or both [35]. Meanwhile, the crystalline quality of samples has been found to increase constantly with the $\mathrm{pH}$ value. It is evident that the decrease in strain causes the increase in crystal size through line broadening.

In order to strengthen the XRD analysis, further, the volume of the nanoparticles has been calculated from the relation $V=(4 / 3) \pi(D / 2)^{3}$ and the volume of hexagonal unit cell from $v=\left(3 a^{2} c\right) / 2$. Then, the ratio $V / v$ gives the number of unit cell present in a particle, which has been calculated from the equation $n=1.621\left(D^{3} / a^{2} c\right)$. Further, the $\mathrm{Zn}-\mathrm{O}$ bond length $(L)$ has been calculated by the relation,

$L=\sqrt{0.3 a^{2}+(0.5-u)^{2} c^{2}}$,

where $u=\frac{a^{2}}{3 c^{2}}+0.25$.

In this equation, $u$ is known as internal parameter (zcoordinate of the oxygen atoms) of the wurtzite structures. $\mathrm{Zn}-\mathrm{O}$ bond length was found to be $1.8935,1.8895,1.8939$ and $1.8895 \AA$ for the $\mathrm{pH}$ value of $6,8,12$ and 13 , respectively. All the details calculated from XRD pattern is given in Table 1.

\subsection{Analysis of UV-Vis Absorption Spectrum}

The optical absorption spectrum of the prepared samples recorded at visible and ultraviolet region is shown in Fig. 2. The recorded absorption peak $\left(\lambda_{\mathrm{ab}}\right)$ for the samples prepared at $\mathrm{pH}$ value of $6,8,12$ and 13 are $361,368,374$ and $381 \mathrm{~nm}$, respectively. As seen, $\lambda_{\mathrm{ab}}$ increases gradually with the $\mathrm{pH}$ value. The absorption peaks of all the samples reported here are lower than that of bulk $\mathrm{ZnO}(388 \mathrm{~nm})$, which corresponds to the blue shift in the spectrum. This blue shift in the excitonic absorption favors for the little quantum confinement effect [36], since the size of the nanoparticle under study is much larger than the Bohr radius of $\mathrm{ZnO}$ (approximately $2.34 \mathrm{~nm}$ ) [37]. Furthermore, the energy gap of the nanoparticles has been calculated using the relation $E_{\mathrm{g}}=\left(1,243 / \lambda_{\mathrm{ab}}\right)$, and it was found to be $3.43,3.37,3.32$ and $3.25 \mathrm{eV}$ for the samples of $\mathrm{pH}$ value of $6,8,12$ and 13 , respectively. As the energy gap is inversely proportional to $\lambda_{\mathrm{ab}}$, measurement demonstrates that the sample synthesized at $\mathrm{pH}$ value 6 has the largest energy gap of $3.43 \mathrm{eV}$, whereas the sample synthesized at $\mathrm{pH}$ value of 13 has the lowest energy gap of $3.25 \mathrm{eV}$. Thus, the energy gap measurement relays that the particle size increases with $\mathrm{pH}$ value.

The spectrum also indicates that the sample synthesized by chemical precipitation method has a very high level of purity. The presence of any contaminants would have acted as dopants in the $\mathrm{ZnO}$, causing lower energy (higher wavelength) transitions, which would appear as small peaks or drops in the UV-Vis spectrum. But the spectrum shows a smooth line beyond the original drop. It proves that the precipitation method provides high purity $\mathrm{ZnO}$ nanoparticles.

\subsection{Transmittance Spectrum and Tauc's Relation}

Optical transmittance spectrum of the prepared samples is shown in Fig. 3. From the figure, it is clear that the $\mathrm{pH}$ value has some influence on the optical transmittance of the $\mathrm{ZnO}$ nanoparticles. Obviously, the sample synthesized at $\mathrm{pH}$ value of 6 has the minimum transmittance of $20 \%$, and the sample synthesized at $\mathrm{pH}$ value of 8 has the maximum transmittance of $65 \%$. Further increase in $\mathrm{pH}$ value decreased the transmittance and finally it reached $\sim 30 \%$ at $\mathrm{pH}$ value of 13 . It is interesting to note that the transmittance is almost uniform between 250 and $750 \mathrm{~nm}$ for the samples synthesized at $\mathrm{pH}$ value of 6,12 and 13. But for the $\mathrm{pH}$ value of 8 , the transmittance is low below $350 \mathrm{~nm}$ and it increases exponentially, till $750 \mathrm{~nm}$. This obvious trend suggests that the $\mathrm{ZnO}$ nanoparticles prepared at $\mathrm{pH}$ value of 6 can act as a strong UV absorber for wavelengths shorter than $350 \mathrm{~nm}$.

In addition to the correlation between $\mathrm{pH}$ value and transmittance, energy gap of the prepared samples has also been evaluated using the Tauc's relation [38]

$\left(\boldsymbol{\alpha} \boldsymbol{h}_{v}\right)^{2}=A\left(\boldsymbol{h}_{v}-E_{\mathrm{g}}\right)$,

where $A$ is a constant, $\boldsymbol{h}_{v}$ is the energy of the photon, $\alpha$ is the absorption coefficient $(\alpha=4 \pi k / \lambda ; k$ is the absorption index), $E_{\mathrm{g}}$ is the energy gap of the nanoparticles under investigation, which is shown in the Fig. 4. It is estimated from the intercept of the linear portion of the curve on $x$ axis. Estimated $E_{\mathrm{g}}$ to be $3.42 \mathrm{eV}$ for the sample at $\mathrm{pH}$ value of 6 and it decreases to 3.393 .38 and $3.38 \mathrm{eV}$ on further increase in $\mathrm{pH}$ value to 13 , which are very close to our earlier report $[39,40]$. The energy gap measurement from the UV-Vis absorption spectrum and effective mass model equation is in good agreement with Tauc's relation and is shown in Table 2.

\subsection{Morphology and Compositional Analysis}

SEM images of the prepared $\mathrm{ZnO}$ nanoparticles are shown in Fig. 5. A strong effect of $\mathrm{pH}$ value on the crystalline growth is clearly observed from the micrograph. It is found that the surface morphology of the particle is improved with increasing $\mathrm{pH}$ value. At lower $\mathrm{pH}$ value, the size distribution of particles appears to be less homogenous. It 

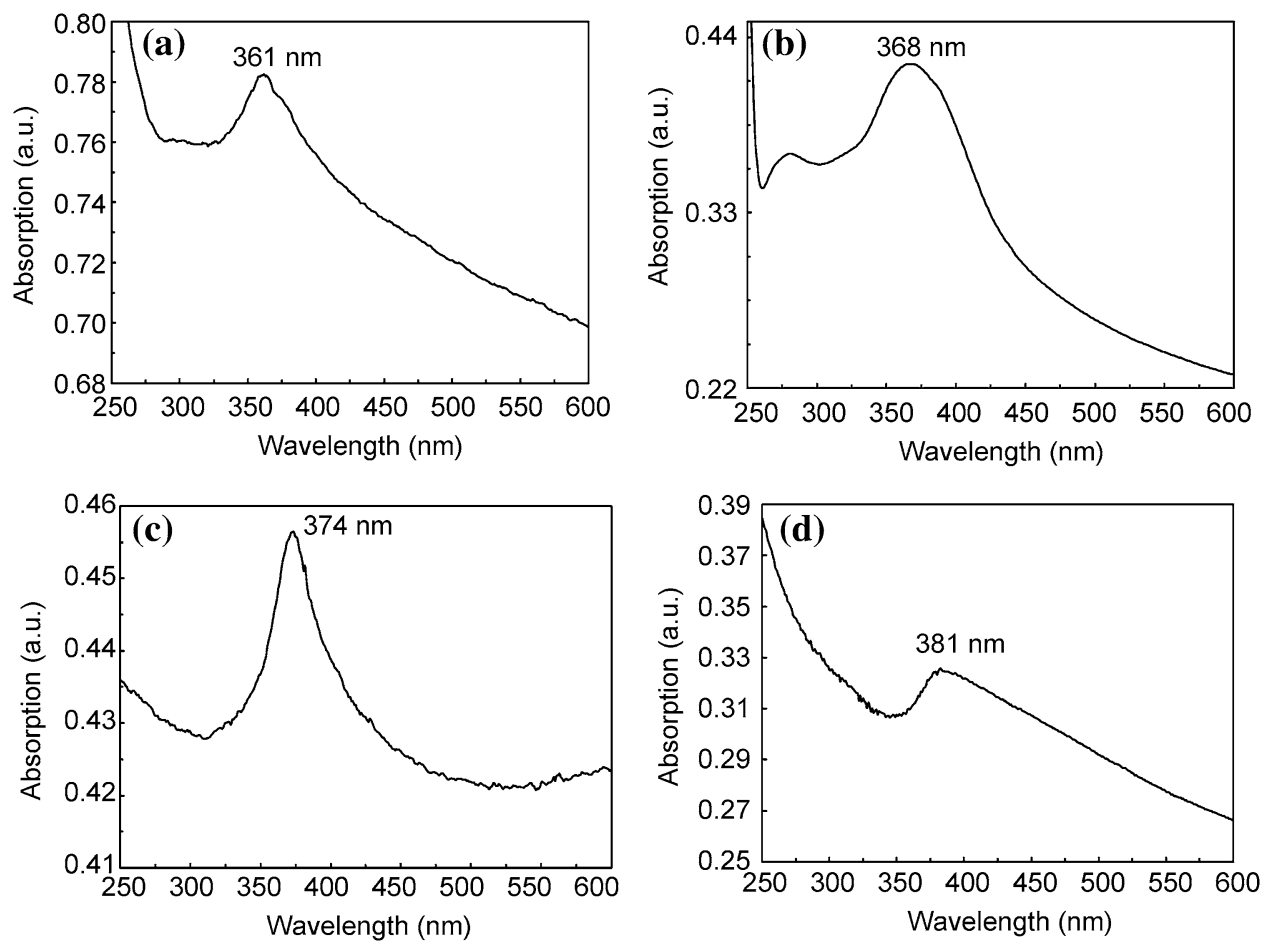

Fig. 2 UV-Vis absorption characteristics of $\mathrm{ZnO}$ nanoparticles synthesized at different $\mathrm{pH}$ values: a pH 6; b $\mathrm{pH} 8$; $\mathbf{c} \mathrm{pH} 12$; d pH 13

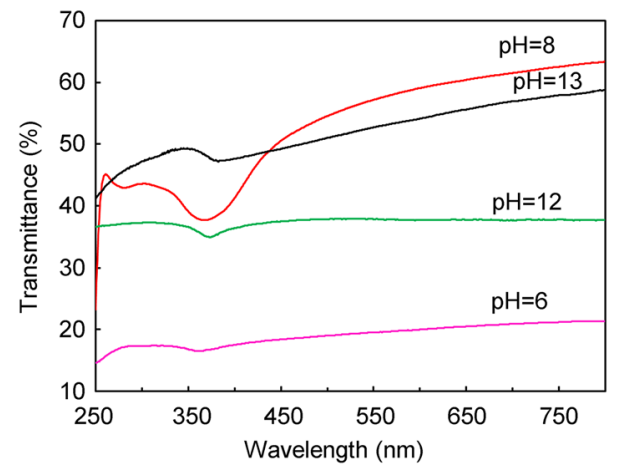

Fig. 3 Optical transmittance versus wavelength of $\mathrm{ZnO}$ samples synthesized at different $\mathrm{pH}$ values

is well known that nanoparticles are prone to aggregate due to the surface area to volume ratio; many primary nanoparticles combined themselves during the crystallization, which results in large bulk particles with severe agglomeration at $\mathrm{pH}$ value of 6 . Such kind of agglomeration was previously reported $[30,32]$.

Morphology of particles is found to be roughly spherical and homogenous and some of the particles have agglomerated even when the $\mathrm{pH}$ value is increased to 8 . Further increase in $\mathrm{pH}$ value to 12 resulted nanoparticles of different size; a few of them are spherical but majority of the particles are in rod-like structure. At $\mathrm{pH}$ value is 13 , there is no agglomeration and all the particles are individual and uniform in size. Most interesting thing to be considered here is that the sample prepared at $\mathrm{pH}$ value of 13 contains the particles of hexagonal facet. Magnified version of one such hexagonal facet, enclosed by dotted circle, is highlighted in the inset. Measurement reveals that the average particle size is 23,36 and $43 \mathrm{~nm}$ for samples synthesized at the $\mathrm{pH}$ value of 812 and 13, respectively. Particle size measured with SEM is in close agreement with that of XRD analysis. SEM analysis also reveals that the particle size increases with the increase in $\mathrm{pH}$ value. This observation is exactly opposite to some other experiment. For instance, as stated in introduction, Rani et al. [29] noticed a decrease in particle size when $\mathrm{pH}$ value higher than 9 . They suggested that the dissolution of $\mathrm{ZnO}$ would take place at higher $\mathrm{pH}$ value, thereby decreases the particle size. But in our case, particle size increases consistently till $\mathrm{pH}$ value reach 13 . Therefore, we believed that dissolution of $\mathrm{ZnO}$ didn't occur even at higher $\mathrm{pH}$ value of 13 . As a result, many smaller nanocrystals combined themselves and formed a larger particle. Figure 6a shows a typical TEM image of $\mathrm{ZnO}$ nanoparticles grown at $\mathrm{pH}$ value of 12 , from which the sphere-like morphology could be identified clearly and the average size of the nanoparticles are estimated to be about $25 \mathrm{~nm}$.

Energy dispersive spectra (EDS) shown in the Fig. 6b-d depict the results of composition analysis of the samples prepared at $\mathrm{pH}$ values of 6,8 and 13. Seeing that similar spectrum was recorded for all the samples, only three spectra are displayed here. The spectra corresponds the 

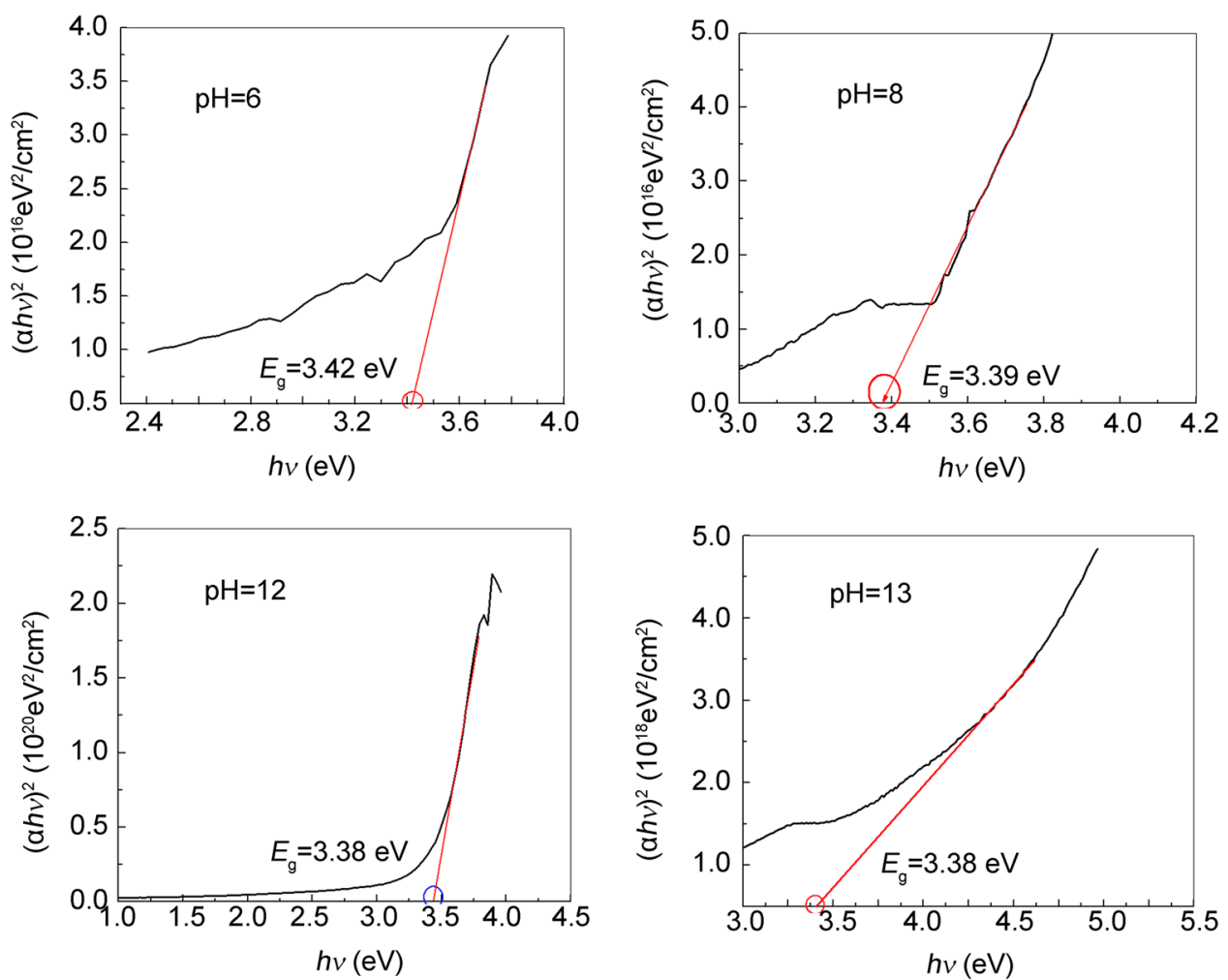

Fig. 4 Energy gap of the $\mathrm{ZnO}$ nanoparticles synthesized at different $\mathrm{pH}$ values

peaks of zinc $(\mathrm{Zn})$, oxygen $(\mathrm{O})$ and carbon $(\mathrm{C})$. Moreover, there are some other small peaks which show that the synthesized samples contains small amount of impurity still. It is evident that the synthesized nanoparticles have $\mathrm{Zn}$ and $\mathrm{O}$. Result of composition analysis is given in Table 3.

\subsection{FT-IR Studies}

Result of FT-IR analysis of prepared $\mathrm{ZnO}$ particles is displayed in Fig. 7. A series of absorption peaks from 4,000 to $1,000 \mathrm{~cm}^{-1}$ can be found, corresponding to the vibration modes of impurities such as hydroxyl, carboxylate, carboxyl and alkane present in the nanopowders. To be more specific, the spectra show main absorption bands at $3,290-3,420 \mathrm{~cm}^{-1}$ represents $\mathrm{O}-\mathrm{H}$ stretching vibration of water [41] from $\mathrm{NaOH}$ (used as a precursor) and those at 2,934 $\mathrm{cm}^{-1}$ represents the $\mathrm{C}-\mathrm{H}$ stretching vibrations of alkane groups. The peak at about $2,201-2,358 \mathrm{~cm}^{-1}$ arises from the atmospheric $\mathrm{CO}_{2}$ on the metallic cations. However, this peak hasn't been observed at $\mathrm{pH}$ 12. The peak observed around $1,707 \mathrm{~cm}^{-1}$ of samples prepared at $\mathrm{pH}$ value of 6 and 12 are due to carboxyl group. Small peaks recorded between 1,646 and $1,542 \mathrm{~cm}^{-1}$ are probably from $\mathrm{C}=\mathrm{O}$ band. Similarly, the absorption peaks at $1,425-1,495 \mathrm{~cm}^{-1}$ represents the carboxylate group $\left(\mathrm{COO}^{-}\right)$. The band around $1,388 \mathrm{~cm}^{-1}$ is the representative of bending vibration of $-\mathrm{CH}_{2}$. Moreover, the band at $\sim 1,273 \mathrm{~cm}^{-1}$ corresponds the $\mathrm{O}-\mathrm{H}$ symmetric bending. The $\mathrm{C}-\mathrm{H}$ in plane bending vibration has been noticed at $1,112 \mathrm{~cm}^{-1}$ only from the sample prepared at $\mathrm{pH}$ value of 13 . The peaks around $1,020-1,044 \mathrm{~cm}^{-1}$ depict the stretching vibration of $\mathrm{C}-\mathrm{O}$ attributed to zinc acetate. The band centered at 815,883 and $914 \mathrm{~cm}^{-1}$ is attributed to bending mode of carbonate.

In the infrared region, characteristic $\mathrm{Zn}-\mathrm{O}$ stretching mode was found at the wave number between 482 and $595 \mathrm{~cm}^{-1}$. This difference in wavenumber may be due to difference in particle sizes and the frequencies are consistent with those reported in the literature [42]. These stretching mode peaks are indicative of the successful synthesis of $\mathrm{ZnO}$ nanoparticles. IR Peak assignments for various functional groups are displayed in Table 4. As the size of the nanoparticles increases, the FTIR signature of these impurities decreases.

\subsection{PL Spectrum of the ZnO Nanoparticles}

Photoluminescence study helps to find out the structural defects in nanoparticles. It is well known that the PL intensity depends on the particle density in the solvent. In order to analyze the impact of $\mathrm{pH}$ value on PL intensity, $150 \mathrm{mg}$ of $\mathrm{ZnO}$ nanopowder from each sample has been dispersed in $15 \mathrm{~mL}$ double distilled water, and then, the 
spectrum has been recorded. Figure 8 displays the PL spectra of samples under study. As expected, each curve depicts the variation of $\mathrm{PL}$ intensity with respect to $\mathrm{pH}$ value. A considerable decrease in $\mathrm{PL}$ intensity with $\mathrm{pH}$ is observed. This variation in PL intensity reveals the transmittance spectra. It can be seen that four emission bands were observed in all the samples such as (1) UV emission $(<400 \mathrm{~nm})$ band, (2) violet emission (430 nm) band, (3) blue emission $(487 \mathrm{~nm})$ band and (4) a weak but broad green emission $(513 \mathrm{~nm})$. Of these, UV emission is known as a near-band-edge (NBE) emission, which originates from the recombination of free exciton through an excitonexciton collision process.

The characteristic UV emission (399 nm) of $\mathrm{ZnO}$ nanoparticles has been observed at $399 \mathrm{~nm}$ in all the cases. It can be seen that, the UV region starts widen with $\mathrm{pH}$ value and it is wider at $\mathrm{pH}$ value of 13. It shows that the sharp UV peaks can be obtained at lower $\mathrm{pH}$ value. Also, it is clear that UV

Table 2 Energy gap (in eV) measurements from different methods of the $\mathrm{ZnO}$ nanoparticles synthesized at various $\mathrm{pH}$ values

\begin{tabular}{llll}
\hline $\begin{array}{l}\mathrm{pH} \\
\text { value }\end{array}$ & $\begin{array}{l}\text { Effective mass } \\
\text { model }\end{array}$ & $\begin{array}{l}\text { UV-Vis } \\
\text { spectrum }\end{array}$ & $\begin{array}{l}\text { Tauc's } \\
\text { relation }\end{array}$ \\
\hline 6 & 3.42 & 3.43 & 3.42 \\
8 & 3.40 & 3.37 & 3.39 \\
12 & 3.39 & 3.32 & 3.38 \\
13 & 3.38 & 3.25 & 3.38 \\
\hline
\end{tabular}

emission is dominant at lower $\mathrm{pH}$ value of 6 whereas the violet emission dominates when the $\mathrm{pH}$ value higher than 8 . It is due to the fact that the lower $\mathrm{pH}$ value correspond the higher concentration of $\mathrm{H}^{+}$ions which facilitates higher concentration of hydrogen dopants incorporated into the lattice of $\mathrm{ZnO}$ [4] which further contributes to the stronger UV (NBE) intensity as hydrogen dopants [5]. The violet emission band observed in all the samples between 423 and $448 \mathrm{~nm}$ is attributed to the presence of zinc interstitials $\left(\mathrm{Zn}_{\mathrm{i}}\right)$ shallow donors, which have a $0.22 \mathrm{eV}$ energy gap below the conduction band. Exciton recombination between the electrons localized at the zinc interstitials and holes in the valence band leads to this violet emission. This type of violet emission band was also observed in the $\mathrm{ZnO}$ nanoneedle arrays reported by Ahn et al. [43]. In addition to violet, blue emission has been observed sharply around $487 \mathrm{~nm}$ in all the samples. Meanwhile, the weak green emission covers a wide of $513-540 \mathrm{~nm}$. From the present study, it is clear that increase of $\mathrm{pH}$ value i.e., increase of particle size is favorable for the violet emission and it widens the UV emission range from 399 to $417 \mathrm{~nm}$ (Refer curve d in Fig. 8), but it does not affect blue and green emissions. Therefore, the photoluminescence study reported here concludes that the type of emission from the $\mathrm{ZnO}$ nanoparticles, i.e., whether $\mathrm{UV}$ (or) violet is determined by the $\mathrm{pH}$ value of the solution. Also, the strong violet and weak blue bands emitted by the samples confirm that the prepared samples contain the $\mathrm{ZnO}$ nanoparticles.
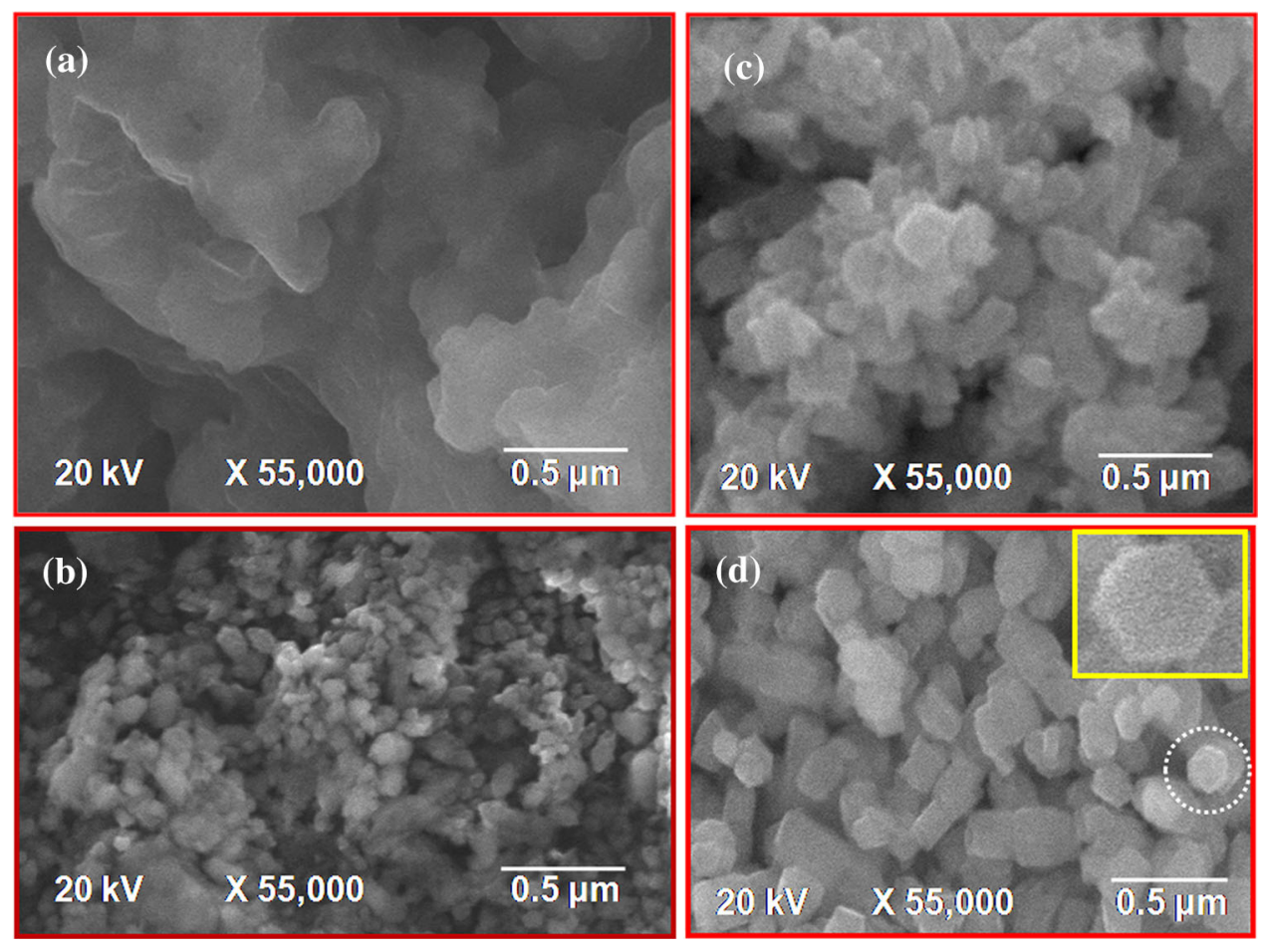

Fig. 5 SEM images of $\mathrm{ZnO}$ nanoparticles synthesized at various $\mathrm{pH}$ values: a pH 6; b pH 8; c pH 12; d pH 13 

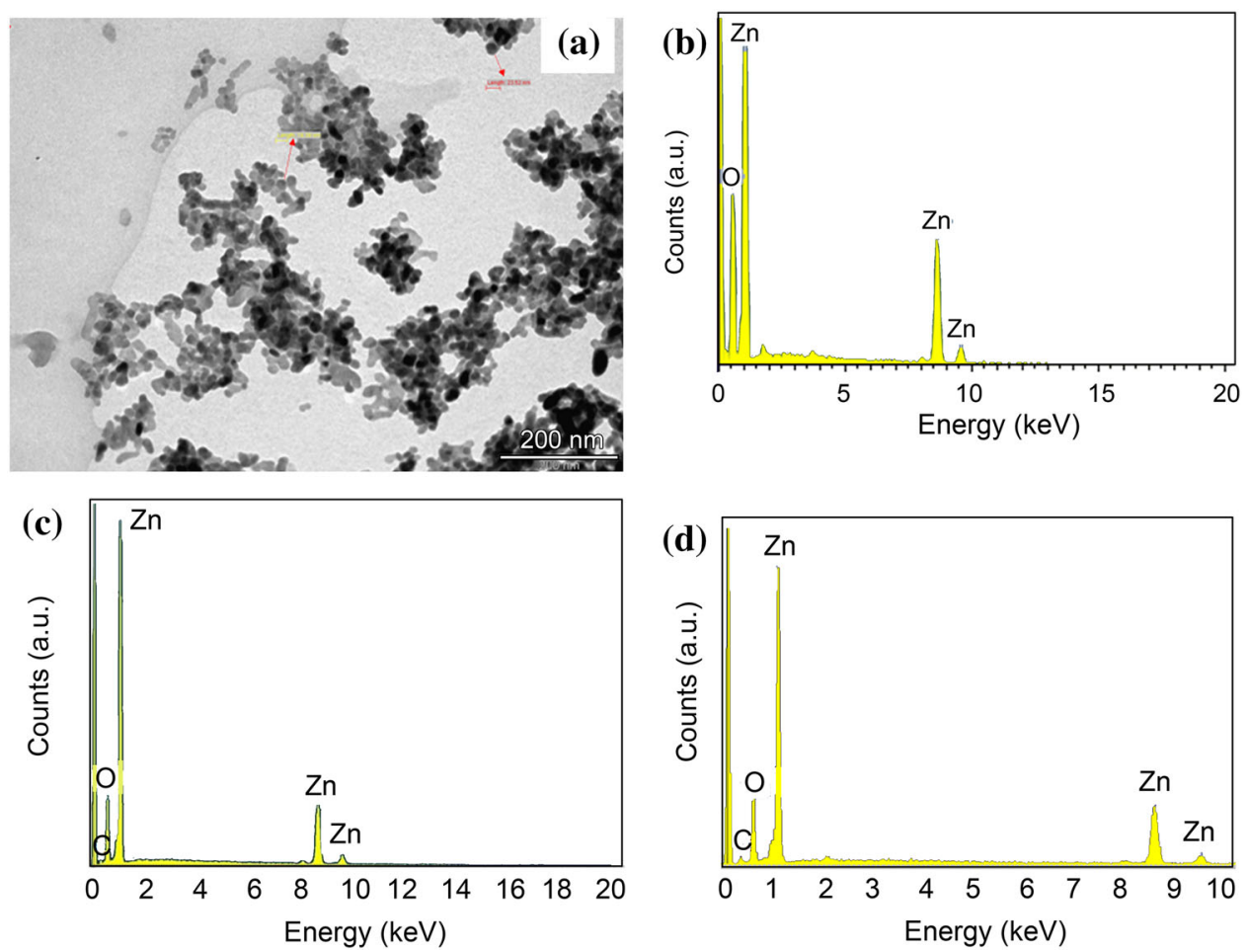

Fig. 6 TEM image of the $\mathrm{ZnO}$ nanocrystals synthesized at pH 12 a, EDS spectra of $\mathrm{ZnO}$ nanocrystals synthesized at $\mathrm{pH} 6 \mathbf{b}$, pH 8 c, pH 13 d

Table 3 Results of elemental analysis of the $\mathrm{ZnO}$ nanoparticles synthesized at various $\mathrm{pH}$ values

\begin{tabular}{lll}
\hline $\mathrm{pH}$ value & $\mathrm{Zn} K(\mathrm{wt} \%)$ & $\mathrm{O} K(\mathrm{wt} \%)$ \\
\hline 6 & 60.28 & 39.72 \\
8 & 63.18 & 36.82 \\
12 & 66.77 & 33.23 \\
13 & 68.83 & 31.17 \\
\hline
\end{tabular}

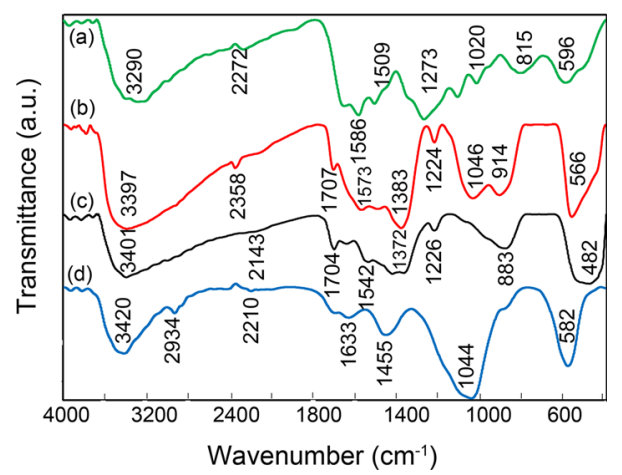

Fig. 7 Typical FTIR spectrum and their peak assignments of $\mathrm{ZnO}$ nanoparticles synthesized at various $\mathrm{pH}$ values: $a \mathrm{pH} 6 ; b \mathrm{pH} 8 ; c \mathrm{pH}$ $12 ; d \mathrm{pH} 13$

Several groups have reported different defect centers in $\mathrm{ZnO}$ that are responsible for the blue and green visible emissions [44]. This visible emission is due to an electronic transition from a level close to the conduction band edge to a defect associated trap state, such as an oxygen vacancy. According to Vanheusden et al. [45], visible luminescence of $\mathrm{ZnO}$ is mainly originated from the defect states such as oxygen vacancies and zinc interstitials. Oxygen, normally, exhibit three types of charge states such as $V_{\mathrm{o}}^{0}, V_{\mathrm{o}}^{+}$, and $V_{\mathrm{o}}^{2+}$. The oxygen vacancies are situated below the bottom of the conduction band $(\mathrm{CB})$ in the series of $V_{\mathrm{o}}^{0}, V_{\mathrm{o}}^{+}$, and $V_{\mathrm{o}}^{2+}$, from top to bottom. It was recently reported that the transition involving zinc vacancy would result in blue emission [46]. Here, a sharp blue emission peak has been noticed exactly at $487 \mathrm{~nm}$, and this peak occupies the same position irrespective of the $\mathrm{pH}$ value. A broad green emission band between 513 and $540 \mathrm{~nm}$, known as a deep-level emission, is related to the deep-level defect states [47]. This green emission originates from the recombination of a photo-generated hole with an electron, occupying the oxygen vacancy and interstitials of zinc. Shallow acceptor levels lie at 0.3 and $0.4 \mathrm{eV}$ above the top of the valance band (VB) due to zinc vacancy $\left(V_{\mathrm{Zn}}\right)$ and oxygen interstitial $\left(\mathrm{O}_{\mathrm{i}}\right)$, respectively. Again, Zinc interstitial $\left(\mathrm{Zn}_{\mathrm{i}}\right)$ produces a shallow donor level at $0.5 \mathrm{eV}$ below the bottom of CB [48]. The position of different defect levels is illustrated in Fig. 9. In this study, the less intense green emission peaks were observed 513-540 $\mathrm{nm}$ in all the samples. As a result, the present $\mathrm{PL}$ study infers that $\mathrm{pH}$ of the solution has high impact on the luminescence property of the $\mathrm{ZnO}$ sample. 
Table 4 Peak assignments for the prepared $\mathrm{ZnO}$ nanoparticles synthesized at various $\mathrm{pH}$ values

\begin{tabular}{|c|c|c|c|c|}
\hline \multirow[t]{2}{*}{ Functional group } & \multicolumn{4}{|c|}{ Wavenumber $\left(\mathrm{cm}^{-1}\right)$} \\
\hline & $\mathrm{pH} 6$ & $\mathrm{pH} 8$ & pH 12 & $\mathrm{pH} 13$ \\
\hline $\mathrm{O}-\mathrm{H}$ stretching of water & 3,290 & 3,397 & 3,401 & 3,420 \\
\hline $\mathrm{C}-\mathrm{H}$ stretching vibration & - & - & - & 2,934 \\
\hline Existence of $\mathrm{CO}_{2}$ & 2,272 & 2,358 & - & 2,201 \\
\hline Carboxyl group & - & 1,707 & 1,704 & - \\
\hline $\mathrm{C}=\mathrm{O}$ band & $1,585-1,509$ & 1,573 & $1,646-1,542$ & 1,633 \\
\hline Carboxylate group (COO-) & - & 1,495 & 1,425 & 1,465 \\
\hline Bending vibration of $-\mathrm{CH}_{2}$ & - & 1,383 & 1,372 & - \\
\hline $\mathrm{O}-\mathrm{H}$ symmetric bending & 1,273 & 1,224 & 1,225 & - \\
\hline $\mathrm{C}-\mathrm{H}$ in plane bending vibration & 1,112 & - & - & - \\
\hline Stretching vibration of $\mathrm{C}-\mathrm{O}$ & 1,020 & 1,040 & - & 1,044 \\
\hline Bending mode of carbonate & 815 & 914 & 883 & 860 \\
\hline Stretching vibration of $\mathrm{Zn}-\mathrm{O}$ & 596 & 566 & 482 & 582 \\
\hline
\end{tabular}

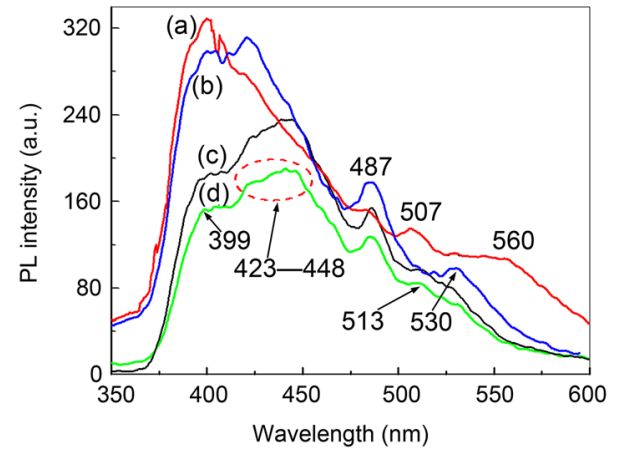

Fig. 8 Room temperature photoluminescence spectrum of the $\mathrm{ZnO}$ nanoparticles synthesized at various $\mathrm{pH}$ values: $a \mathrm{pH} 6 ; b \mathrm{pH} 8 ; c \mathrm{pH}$ $12 ; d \mathrm{pH} 13$

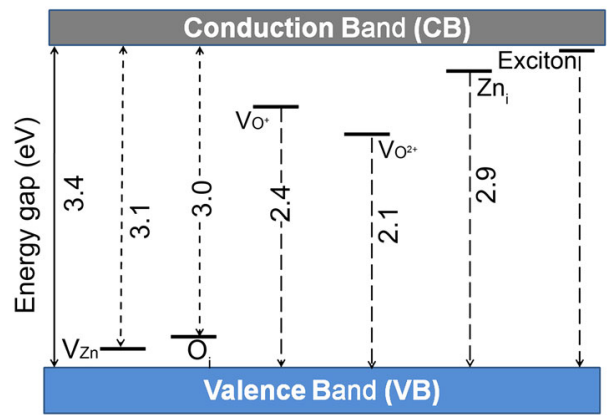

Fig. 9 Schematic illustration of different defect levels in $\mathrm{ZnO}$, which are responsible for the emission of different wavelength

\section{Conclusions}

In conclusion, nanocrystalline $\mathrm{ZnO}$ powders have been successfully synthesized by chemical precipitation method at four different $\mathrm{pH}$ values. The result presented here confirms that $\mathrm{pH}$ value of the solution plays a major role in determining the structure, morphology and optical properties of the $\mathrm{ZnO}$ nanoparticles. The XRD pattern and SEM images confirmed the presence of crystalline wurtzite nanocrystals and also it confirmed that the particle size increases with $\mathrm{pH}$ value. TEM result also favors for the $\mathrm{XRD}$ analysis. The result of UV-Vis spectrum also justified that the prepared $\mathrm{ZnO}$ powders have particles in nanometer size. As the UV-Vis absorption of $\mathrm{ZnO}$ nanoparticles prepared at $\mathrm{pH}$ value of 6 is higher than the other particles, which concludes that $\mathrm{ZnO}$ nanoparticles with smaller size can be used as a UV absorber. From PL study, it is concluded that the $\mathrm{pH}$ value variation would affect the UV and Violet emission, but not the blue and green emissions. Finally, it is concluded that the $\mathrm{ZnO}$ nanoparticles prepared by chemical precipitation method at $\mathrm{pH}$ value of 13 is suitable for the construction of optoelectronic devices for violet emission.

\section{References}

[1] M.A. Subhan, M.R. Awal, T. Ahmed, M. Younus, Acta Metall. Sin. (Engl. Lett.) 27, 223 (2014)

[2] Y. Yao, Q. Cao, Acta Metall. Sin. (Engl. Lett.) 26, 467 (2013)

[3] X. Huang, G. Li, B. Cao, M. Wang, C. Hao, J. Phys. Chem. C 113, 4381 (2009)

[4] X.H. Huang, C.B. Tay, Z.Y. Zhan, C. Zhang, L.X. Zheng, T. Venkatesan, S.J. Chua, Cryst. Eng. Commun. 13, 7032 (2011)

[5] X.H. Huang, Z.Y. Zhan, K.P. Pramoda, C. Zhang, L.X. Zheng, S.J. Chua, Cryst. Eng. Commun. 14, 5163 (2012)

[6] X.H. Huang, C. Zhang, C.B. Tay, T. Venkatesan, S.J. Chua, Appl. Phys. Lett. 102, 111106 (2013)

[7] C.Y. Luan, Y.K. Liu, Y. Jiang, J.S. Jie, I. Bello, S.T. Lee, J.A. Zapien, Vacuum 86, 737 (2012)

[8] A. Choi, K. Kim, H.I. Jung, S.Y. Lee, Sens. Actuators B 148, 577 (2010) 
[9] Y.L. Wu, C.S. Lim, S. Fu, A.I.Y. Tok, H.M. Lau, F.Y.C. Boey, Nanotechnology 18, 215604 (2007)

[10] H. Hong, J. Shi, Y. Yang, Y. Zhang, J.W. Engle, R.J. Nickles, X. Wang, Nano Lett. 11, 3744 (2011)

[11] B. Kumar, S.W. Kim, Nano Energy 1, 342 (2012)

[12] J. Han, F. Fan, C. Xu, S. Lin, M. Wei, X. Duan, Z.L. Wang, Nanotechnology 21, 405203 (2010)

[13] M. Chen, Z. Wang, D. Han, F. Gu, G. Guo, J. Phys. Chem. C 115, 12763 (2011)

[14] C. Wongchoosuk, S. Choopun, A. Tuantranont, T. Kerdcharoen, Mater. Res. Innov. 13, 185 (2009)

[15] R. Niepelt, U.C. Schroder, J. Sommerfeld, I. Slowik, B. Rudolph, R. Moller, B. Seise, A. Csaki, W. Fritzsche, C. Ronnin, Nanoscale Res. Lett. 6, 511 (2011)

[16] F. Yakuphanoglu, S. Mansouri, Microelectron. Reliab. 51, 2200 (2011)

[17] D.I. Son, B.W. Kwon, D.H. Park, W.S. Seo, Y. Yi, B. Angadi, C.L. Lee, W.K. Choi, Nat. Nanotechnol. 7, 465 (2012)

[18] W.K. Hong, S. Song, D.K. Hwang, S.S. Kwon, G. Jo, S.J. Park, T. Lee, Appl. Surf. Sci. 254, 7559 (2008)

[19] Z.L. Wang, Adv. Mater. 15, 432 (2003)

[20] K. Kasemets, M. Romet, A. Ivask, A. Kahru, Toxicol. Lett. 180, S22310 (2008)

[21] M. Heinlaan, A. Ivask, I. Blinova, H.C. Dubourguier, A. Kahru, Chemosphere 71, 1308 (2008)

[22] V. Aruoja, A. Kahru, H.C. Dubourguier, Toxicol. Lett. 180S, S220 (2008)

[23] J. Zhou, N.S. Xu, Z.L. Wang, Adv. Mater. 18, 2432 (2006)

[24] D.D. Guo, C.H. Wu, H. Jiang, Q.N. Li, X.M. Wang, B.A. Chen, J. Photochem. Photobiol. B 93, 119 (2008)

[25] C. Chena, B. Yua, P. Liub, J.F. Liua, L. Wang, J. Ceram. Process. Res. 12, 420 (2011)

[26] W.J. Li, E.W. Shi, T. Fukuda, Cryst. Res. Technol. 38, 847 (2003)

[27] H. Zhang, D. Yang, X. Ma, Y. Ji, J. Xu, D. Que, Nanotechnology 15, 622 (2004)

[28] C.H. Lu, C.H. Yeh, Ceram. Int. 26, 351 (2000)

[29] S. Rani, P. Suri, P.K. Shishodia, R.M. Mehra, Solar Energy Mater. Solar Cells 92, 1639 (2008)

[30] S.S. Alias, A.B. Ismail, A.A. Mohamad, J. Alloys Compd. 499, $231(2010)$

[31] X.H. Huang, Z.Y. Zhan, X. Wang, Z. Zhang, G.Z. Xing, D.L. Guo, D.P. Leusink, L.X. Zheng, T. Wu, Appl. Phys. Lett. 97, 203112 (2010)
[32] K. Sivakumar, V. Senthil kumar, N. Muthukumarasamy, M. Thambidurai, T.S. Senthil, Bull. Mater. Sci. 35, 327 (2012)

[33] S. Manafi, A. Rouhani, S. Joughehdoust, A. Salehi, in Paper Present in 2nd International Conference on Nanotechnology (NANOCON 2010), Olomouc, Czech Republic, EU, 12-14 Oct 2010

[34] K.F. Lin, H.M. Cheng, H.C. Hsu, L.J. Lin, W.F. Hsieh, Chem. Phys. Lett. 409, 208 (2005)

[35] A. Jagannatha Reddy, M.K. Kokila, H. Nagabhushan, R.P.S. Chakradhar, C. Shivakumar, J.L. Rao, B.M. Nagabhushan, J. Alloys Compd. 509, 5349 (2011)

[36] U. Koch, A. Fojtik, H. Weller, A. Henglein, Chem. Phys. Lett. 122, 507 (1985)

[37] Y. Gu, I. Kuskovsky, M. Yin, S. O’Brien, G.F. Neumark, Appl. Phys. Lett. 85, 3833 (2004)

[38] Tauc. J. (ed.), Amorphous and Liquid Semiconductor (Plenum Press, New York, 1974)

[39] K. Pushpanathan, S. Sathya, M. Jay Chithra, S. Gowthami, R. Santhi, Mater. Manuf. Process. 27, 1334 (2012)

[40] M. Jay Chithra, K. Pushpanathan, M. Loganathan, Mater. Manuf. Process. 29, 771 (2014)

[41] D.M. Fernandes, R. Silva, A.A.W. Hechenleitner, E. Radovanovic, M.A.C. Melo, E.A.G. Pineda, Mater. Chem. Phys. 115, 110 (2009)

[42] F. Ahmed, S. Kumar, N. Arshi, M.S. Anwar, B.H. Koo, C.G. Lee, Funct. Mater. Lett. 4, 1 (2011)

[43] H.A. Ahn, Y.Y. Kim, D.C. Kim, S.K. Mohanta, H.K. Cho, J. Appl. Phys. 105, 013502 (2009)

[44] A.B. Djurisic, Y.H. Leung, K.H. Tam, L. Ding, W.K. Ge, H.Y. Chen, S. Gwo, Appl. Phys. Lett. 88, 103 (2006)

[45] K. Vanheusden, C.H. Seager, W.L. Warren, D.R. Tallant, J.A. Voigt, Appl. Phys. Lett. 68, 403 (1996)

[46] K.H. Tam, C.K. Cheung, Y.H. Leung, A.B. Djurisic, C.C. Ling, C.D. Beling, S. Fung, W.M. Kwok, D.L. Phillips, L. Ding, W.K. Ge, J. Phys. Chem. 110, 20865 (2006)

[47] D. Wang, H.W. Seo, C.C. Tin, M.J. Bozack, J.R. Williams, M. Park, N. Sathitsuksanoh, A.J. Cheng, Y.H. Tzeng, J. Appl. Phys. 99, 113509 (2006)

[48] P.S. Xu, Y.M. Sun, C.S. Shi, F.Q. Xu, H.B. Pan, Nucl. Instrum. Methods Phys. Res. B 199, 286 (2003) 